\title{
Of scrubs and rats
}

he nurses had warned me before I
went to see her.

"Mme St-Laurent? Oh, such a tough patient for such a nice-looking young doctor."

"Mme St-Laurent? Be careful she'll steal things from your pocket if you're not looking."

"Mme St-Laurent? Better wear some armour."

No matter: I was keen, I was fresh, and I was open-minded. As per my preclinical training, I was going to treat each of my patients with dignity, respect and tolerance. Thus determined, I entered Mme St-Laurent's room with a smile on my face and a bright yellow Snoopy tie on my chest.

"Oh great, another medical student. What do you want, Scrubs?" she sneered.

I asked her a few novice questions, some of which she ignored, and others she met with curt replies. "Have I been in the hospital before? Look it up in the chart. ... Who do I live with? That's none of your business. You really are snoopy." Then, turning to two nurses chatting in the hallway, Mme St-Laurent shrieked, "Go find another corner to do your business!" and muttered "whores" under her breath.

Welcome to ward medicine, indeed.

I stammered and ended the interaction weakly. Hiding in the empty nursing station, I looked more thoroughly through her chart. She had a history of physical abuse and drug dependence and was estranged from her family. Were these the sources of her hostility?

The next time I saw her I was again all smiles. "Ugh, you're back. Why do you torment me like this?" But I clung to my pleasant-demeanour policy. I explained everything I was going to ask, everything I was going to do. I tried to empathize and take my time. Her humour became less accusatory and more self-deprecating. I touched her shoulder, squeezed her hand and looked her in the eye. "If you keep smiling like this I'm going to start a nasty rumour that

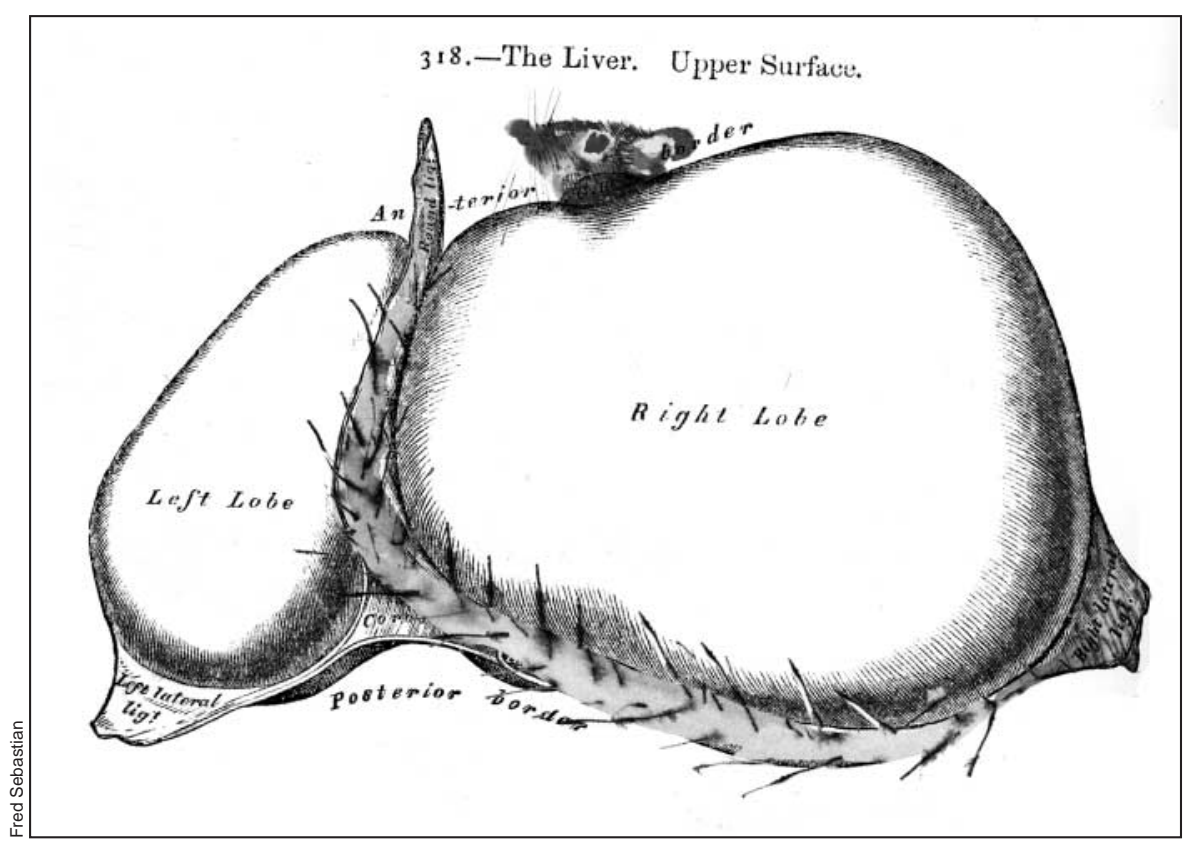

you're actually a very kind woman," I jokingly warned.

She laughed and replied, "You know, I do kinda like you. That's why I don't throw bedpans at you." She motioned to a curved dent in the wall facing her bed. "That was for a nurse who was really annoying me."

I stood silent for a moment, feeling both flabbergasted and thankful.

"Well then, I'm glad I'm on your good side, Mme St-Laurent."

As if to further demonstrate her protective arsenal she added, "And I don't fart at you, either!"

Having completed my exam, and not knowing the correct reply to threats of flatulence, I left the room in a bit of a haze. As a young nurse entered the room to take bloods, I could distinctly hear Mme St-Laurent passing wind.

Mme St-Laurent had lived hard. In social rounds we wondered if she had been a prostitute, if the "ex-husband" she talked about was actually a pimp.

One day a new attending staff physician arrived and chose Mme St-Laurent for bedside learning on examation of the liver. (Her span was $17 \mathrm{~cm}$, the re- sult of hepatitis C infection.) I was intrigued to see how my superiors would interact with her.

As our flurry of white coats stormed into her room, Mme St-Laurent fell disgustedly back into her bed. Then she noticed my pale presence among the group. The attending greeted her. "Mme St-Laurent. We'd like to examine you today."

Completely ignoring him, Mme StLaurent rose to a seated position, frowned, and yelled to me, "So you've brought your curious friends with you, heh, Rat?"

From the disapproving looks on their faces I knew the other members of the team were wondering how I could have forged such a poor alliance with any patient.

Saying nothing in defence of myself, I took solace in Mme St-Laurent's contracted sphincter and the bed pan resting peacefully on the floor.

\section{Eric Cadesky}

PGY-1, Family Medicine

McGill University

Montréal, Que. 